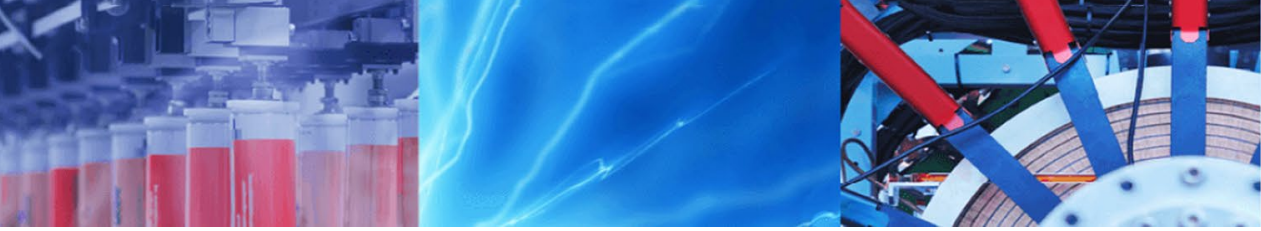

Research Article

\title{
Experimental investigation of forming metallic bipolar plates by hot metal gas forming (HMGF)
}

\author{
Samad Esmaeili ${ }^{1}\left[\right.$. Seyed Jamal Hosseinipour ${ }^{1}$
}

(c) Springer Nature Switzerland AG 2019

\begin{abstract}
In this study, the effects of various parameters in forming of aluminum alloy bipolar plates using hot metal gas forming (HMGF) were studied. The effect of applied gas pressure $P$, channel width $w$, and outer fillet radius of die $R$ were investigated. For evaluation of the forming state, both thickness distribution and filling profile of formed plates were measured. The results showed that increase in the gas pressure led to decrease in the blank thickness and increase in the filling profile. Moreover, by increasing the outer fillet radius, the maximum thickness reduction at formed plates was decreased and filling percentage was increased. Different aspect ratios $\mathrm{h} / \mathrm{w}$ of rigid die were applied. It was concluded that by increasing aspect ratio, the thickness reduction was increased and the filling percentage was decreased. Finally, high accurate plates were fabricated in experimental tests which confirmed the feasibility of forming the thin bipolar plate by HMGF.
\end{abstract}

Keywords Metallic bipolar plates $\cdot$ Hot metal gas forming $\cdot$ Fuel cell $\cdot$ Thickness distribution $\cdot$ Filling profile

\section{Introduction}

Proton exchange membrane fuel cell (PEMFC) stack consists of three main components entitled bipolar plates, membrane and catalyst. These components are the corner stone in establishing the overall cost of the fuel cell. Among all other components, bipolar plates can make an outstanding contribution in determining the weight as well as the fabrication cost of stacks, due to the fact that they consist of $60-80 \%$ of stack weight and $30-45 \%$ of stack cost [1, 2]. Bipolar plates can be divided into three main groups: (1) graphite bipolar plates, (2) polymer-carbon composite bipolar plates, and (3) metallic bipolar plates. Due to possessing some exceptional characteristics such as low fabrication cost and high mechanical properties, metallic bipolar plates are considered as the most common kind of plates in fuel cells [3-5]. Hydroforming, machining, stamping, electroforming, forging and die casting are ordinary methods for fabrication of metallic bipolar plates [6]. It is crystal-clear that channel geometry, size, and pattern have an outstanding influence on the performance of the channel arrays such as heat transfer $[7,8]$. The formation of the micro-channel in every plate is supposed the most critical issue during fabrication of aforementioned plates. Recently, a considerable numbers of fabrication methods of the metallic bipolar plate have been studied. Koc and Mahabunphachai [9] investigated a novel manufacturing process in which the internal pressure consists of hydraulic and mechanical force formed micro-channels and bonded two plates at the same die. Lee et al. [10] fabricated micro-channels by electrochemical micromachining. This method does not have appropriate surface quality. Yokoyama et al. [11] applied hot pressing in the super cooled liquid state in order to forming of metallic bipolar plates. Hung et al. [12] investigated on fabrication of metallic bipolar plates by micro electrical discharge milling. They also studied about the influence of aspect ratio $(\mathrm{h} / \mathrm{w})$ (height of channel $\mathrm{h}$ to its width $\mathrm{w}$ ) on

Samad Esmaeili, samad.esmaeily@gmail.com; Seyed Jamal Hosseinipour, j.hosseini@nit.ac.ir|' Department of Mechanical Engineering, Babol University of Technology, Babol, Mazandaran, Iran.

SN Applied Sciences (2019) 1:187| https://doi.org/10.1007/s42452-019-0202-4

Received: 22 October 2018 / Accepted: 21 January 2019 / Published online: 29 January 2019

SN Applied Sciences

a SPRINGer Nature journal 
Table 1 Chemical composition of blank's material [weight percent (wt\%)]

\begin{tabular}{llllllllllll}
\hline $\mathrm{Si}$ & $\mathrm{Fe}$ & $\mathrm{Cu}$ & $\mathrm{Mn}$ & $\mathrm{Mg}$ & $\mathrm{Cr}$ & $\mathrm{Ni}$ & $\mathrm{Zn}$ & $\mathrm{Ti}$ & $\mathrm{Be}$ & $\mathrm{Ca}$ & $\mathrm{Li}$ \\
0.70 & 0.65 & $<0.01$ & 0.01 & $<0.01$ & 0.02 & 0.01 & 0.03 & 0.008 & Trace & 0.002 & Trace \\
$\mathrm{Pb}$ & $\mathrm{Sn}$ & $\mathrm{Sr}$ & $\mathrm{V}$ & $\mathrm{Na}$ & $\mathrm{Bi}$ & $\mathrm{Co}$ & $\mathrm{Zr}$ & $\mathrm{B}$ & $\mathrm{Ga}$ & $\mathrm{Cd}$ & $\mathrm{Al}$ \\
0.01 & $<0.005$ & $\mathrm{Trace}$ & 0.016 & 0.002 & 0.002 & 0.003 & 0.003 & 0.002 & Trace & 0.003 & Base \\
\hline
\end{tabular}

performance of micro fuel cells. Liu et al. $[13,14]$ applied rubber pad forming method for forming of metallic bipolar plate. This method contains a rubber pad which is forced toward blank in order to forming it according to rigid die pattern. This method is basically outweighing that of traditional blank fabrication process using rigid die set. Lim et al. [15] studied on forming of aluminum bipolar plates with $0.2 \mathrm{~mm}$ in thickness by rubber pad forming process. They also reported the optimal shape for aluminum bipolar plate. Belali-Owsia et al. [16] applied hydroforming, stamping and hybrid hydroforming-stamping method in order to forming of pin-type pattern bipolar plates. Ghadikolaee et al. [17] studied about various parameters of rubber pad forming, such as applied pressure, hardness and thickness of rubber pad in order to achieve the deepest channels before fracturing. In this study, the feasibility of forming metallic bipolar plates using hot metal gas forming(HMGF), as a different method, were studied. For this purpose, the set of die and aluminum alloy blank were fastened together, and heated up to $500{ }^{\circ} \mathrm{C}$. Then, the argon gas entered into the die space and formed the blank according to the die shape. This method has some advantages such as low forming pressure in comparison with conventional forming methods as well as clean work due to oil elimination in comparison with hydroforming. Since argon, which is neutral gas, is applied during forming process, it does not have side-effect on material properties of formed plates.

\section{Material and experimental procedure}

\subsection{Material}

In experimental tests, an aluminum 8111 alloy blank with thickness of $0.2 \mathrm{~mm}$ and diameter of $68 \mathrm{~mm}$ is used. The chemical composition of blank's material is given in Table 1. Moreover, some of the physical and mechanical properties of blank's material at ambient temperature are provided in Table 2 . In ambient temperature, the strain-stress relation can be demonstrated by Eq. (1)

$\sigma=K \varepsilon^{n} \dot{\varepsilon}^{m}$

where $\sigma$ is the equivalent flow stress, $\dot{\varepsilon}$ is the equivalent strain rate, $\varepsilon$ is the equivalent strain, $\mathrm{m}$ is the strain rate sensitivity index, $\mathrm{n}$ is the work-hardening index and $\mathrm{K}$
Table 2 Physical and mechanical properties of blank's material at ambient temperature

Equivalent flow stress Density $(\rho)(\mathrm{kg} / \mathrm{m} 3)$ Specific elongation at $(\sigma)(\mathrm{MPa}) \quad \operatorname{break}(\%)(\delta)$

\begin{tabular}{ll}
\hline 35 & 2710 \\
\hline
\end{tabular}

Table 3 Mechanical properties of blank's material at $500{ }^{\circ} \mathrm{C}$

\begin{tabular}{llll}
\hline $\begin{array}{l}\text { Equivalent flow } \\
\text { stress }(\sigma)(\mathrm{MPa})\end{array}$ & $\begin{array}{l}\text { Coefficient of } \\
\text { resistance }(\mathrm{K})\end{array}$ & $\begin{array}{l}\text { Strain rate } \\
\text { sensitivity index } \\
(\mathrm{m})\end{array}$ & $\begin{array}{l}\text { Equivalent } \\
\text { strain rate }(\dot{\varepsilon})\end{array}$ \\
\hline 6.94 & $14 \times 10^{6}$ & 0.08 & $1.57 \times 10^{-4}$ \\
\hline
\end{tabular}

coefficient of resistance. But at high temperatures, the work hardening index, $\mathrm{n}$ is reduced and Eq. (1) can be replaced with Eq. (2) $[18,19]$

$\sigma=K \dot{\varepsilon}^{m}$

Considering the point that all of the experimental tests were performed at $500{ }^{\circ} \mathrm{C}$, it was crucial to acquire the mechanical properties of blank's material at the same temperature. For this purpose, the free bulging test using HMGF was used $[18,19]$ and all of the parameters of Eq. (2) were calculated. These parameters are shown in Table 3.

\subsection{Experimental procedure}

Overall schematic of hot metal gas forming components is shown in Fig. 1a. The components consist of argon gas container, heating element, temperature sensor, temperature controller, die set, blank and gas pressure valve. The blank is placed between the upper and lower die. The collection is clamped by five screws. After reaching the specified temperature by heating elements, the pressure control valve is opened. Then, the gas transferred behind the blank; so, it compressed the hot blank toward the die to form the hot blank according to the shape of die. The schematic steps of the process are shown in Fig. $1 \mathrm{~b}$. It is obvious that applying gas pressure and preventing gas leakage is one of the most important issues which should be taken into consideration. For this purpose, the knurling process was applied on both upper and lower die surfaces which were in direct contact with blank. Fine diamond 
Fig. 1 a The schematic of hot metal gas forming components, $\mathbf{b}$ steps of the process

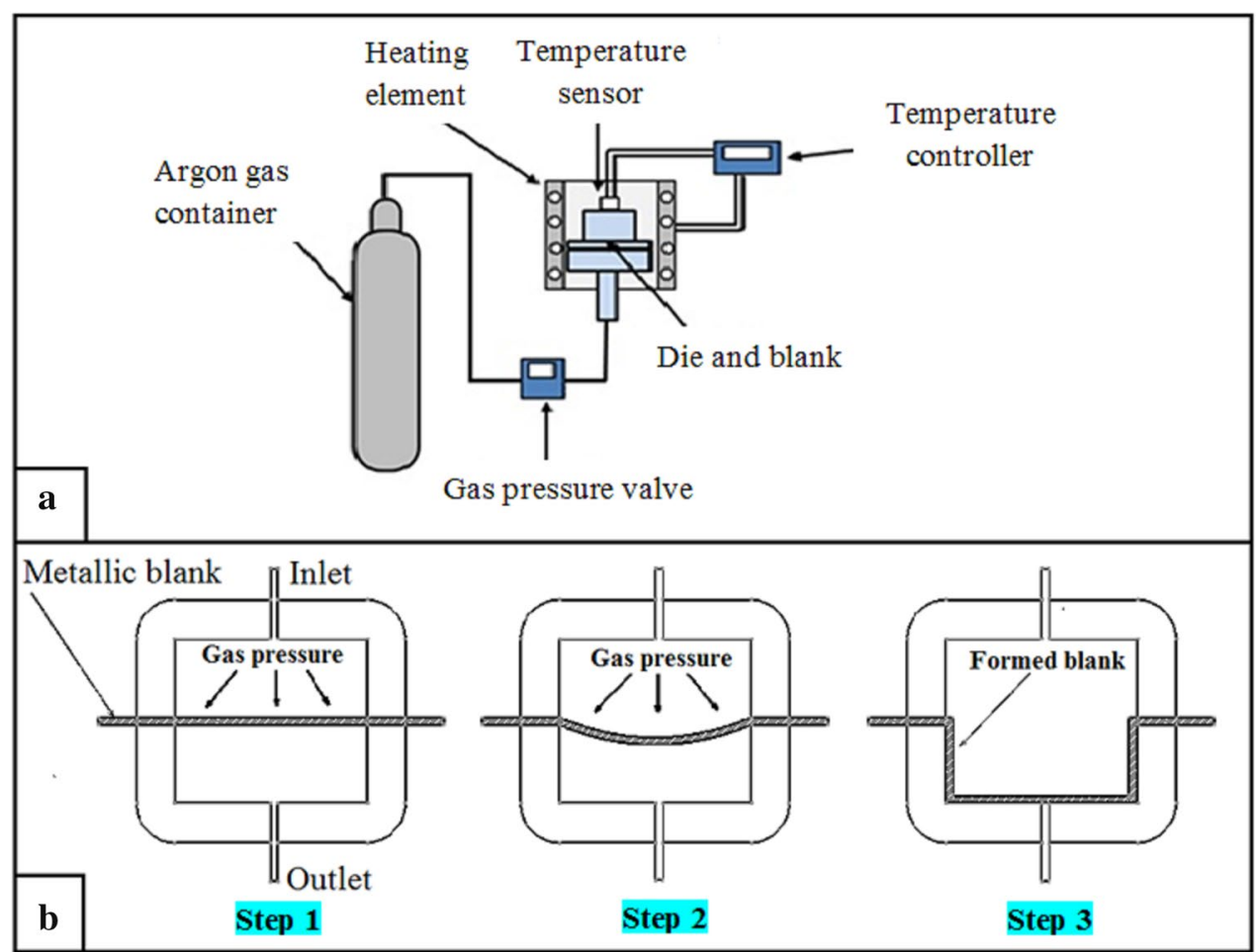

knurling tool has teeth of uniform pitch on cylindrical surface with $30^{\circ}$ helix angle. This pattern with $0.06 \mathrm{~mm}$ depth was applied on die contact surfaces using lathe machine.

During the experiments, some parameters, such as temperature and process time were considered constant at $500{ }^{\circ} \mathrm{C}$ and $15 \mathrm{~min}$ respectively. Equipment and components used in the experiments are shown in Fig. 2.

\subsubsection{Die parameters}

Some parameters play an outstanding role in bipolar plates. According to the studies of Peng et al. [20], the geometric dimensions of micro-channel include the outer fillet radius $\mathrm{R}$, internal fillet radius $r$, flow channel depth $h$, flow channel width $w$, and rib width s. These parameters are shown schematically in Fig. 3. In this study, both the flow channel width w and outer fillet radius $\mathrm{R}$ were considered as variable parameters according to the Table 4. A sample of multi-channel die that is used in experimental tests is depicted in Fig. 4. In hot metal gas forming process, the applied gas pressure has a crucial role in determining the formability of the blank. The experimental tests were performed with variable pressure $P$ varying from 1.8 to $4 \mathrm{MPa}$. During the experiments, the constant and same pressure path was used. The pressure path is shown in Fig. 5. After reaching $500{ }^{\circ} \mathrm{C}$ for die set, by entrance of argon gas in room temperature into the die, the pressure was applied and kept for $15 \mathrm{~min}$; then, the pressure was cut off. After cooling the die set, the formed blank was separated from the die. A sample of formed plate is demonstrated in Fig. 6.

Fig. 2 Experimental equipment

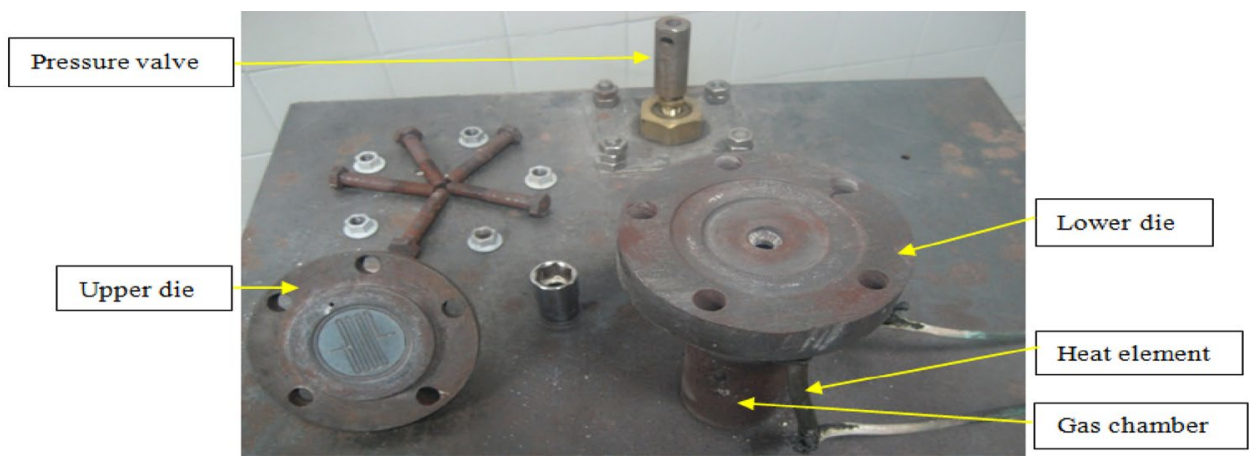




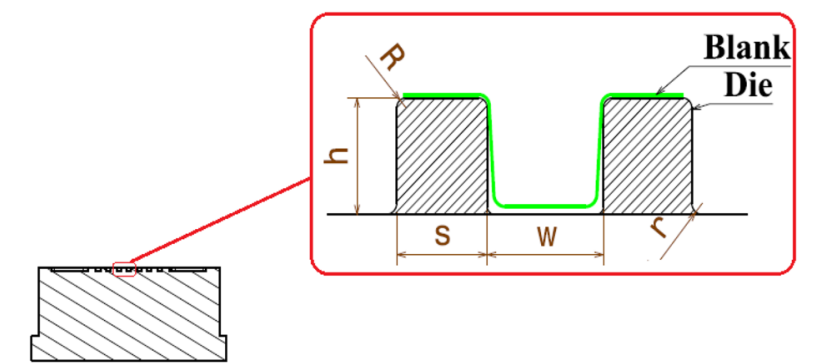

Section view A-A
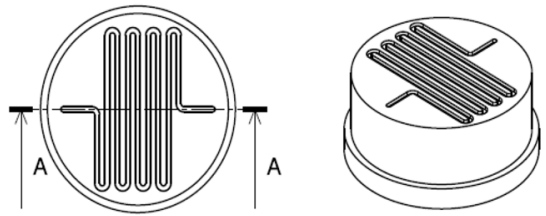

Fig. 3 Geometric dimensions of the micro-channel

Table 4 Range of process and die parameters (dimension in $\mathrm{mm}$ )

\begin{tabular}{llllll}
\hline $\begin{array}{l}\text { Pressure } \\
\mathrm{P}(\mathrm{MPa})\end{array}$ & $\begin{array}{l}\text { Internal } \\
\text { fillet } \\
\text { radius }(\mathrm{r})\end{array}$ & $\begin{array}{l}\text { Outer fil- } \\
\text { let radius } \\
(\mathrm{R})\end{array}$ & $\begin{array}{l}\text { Flow } \\
\text { channel } \\
\text { depth (h) }\end{array}$ & $\begin{array}{l}\text { Rib width } \\
(\mathrm{s})\end{array}$ & $\begin{array}{l}\text { Flow } \\
\text { channel } \\
\text { width }(\mathrm{w})\end{array}$ \\
\hline 1.8 & & & & & \\
2.2 & & 0.1 & & & 1 \\
2.8 & 0.1 & 0.2 & 0.5 & 1.1 & 1.4 \\
3.2 & & 0.3 & & & 1.8 \\
4 & & & & & \\
\hline
\end{tabular}

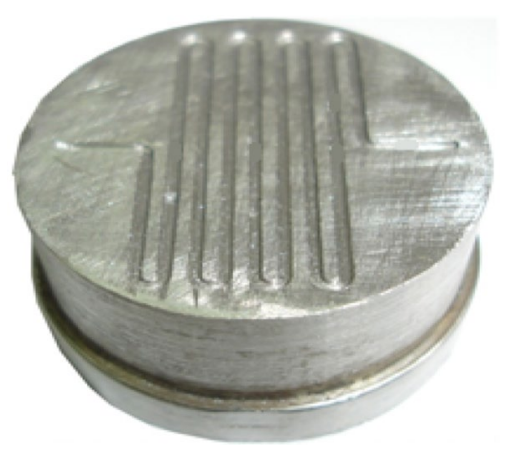

Fig. 4 Multi-channel die for experimental test

\subsubsection{Preparing formed blanks for microscopic investigation}

All formed bipolar plates were cut through the same path by electrical discharge machining. The cutting direction and the cut section of formed plate are shown in Fig. $7 a$ and $b$ respectively. The specimens embedded

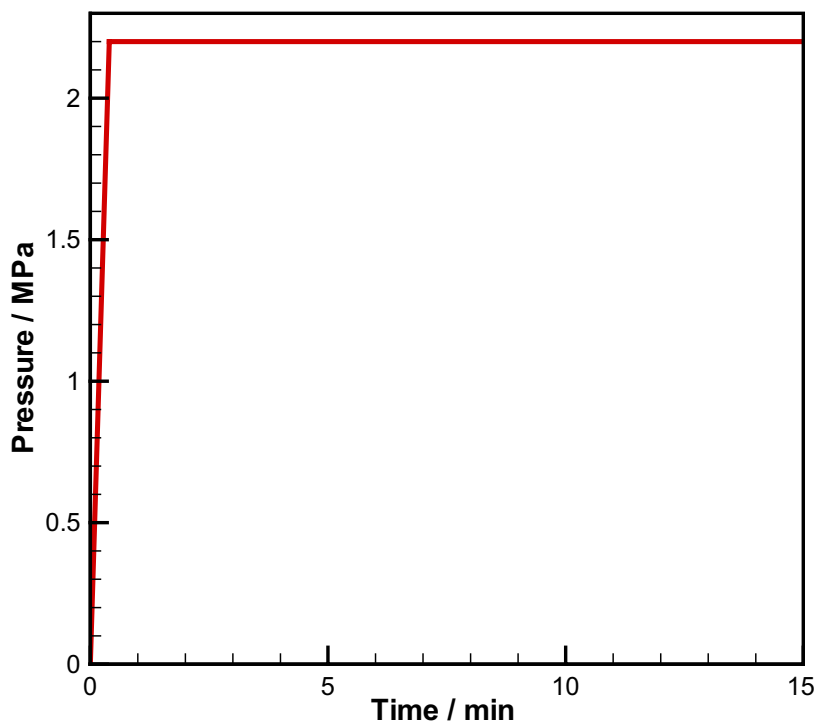

Fig. 5 Pressure path

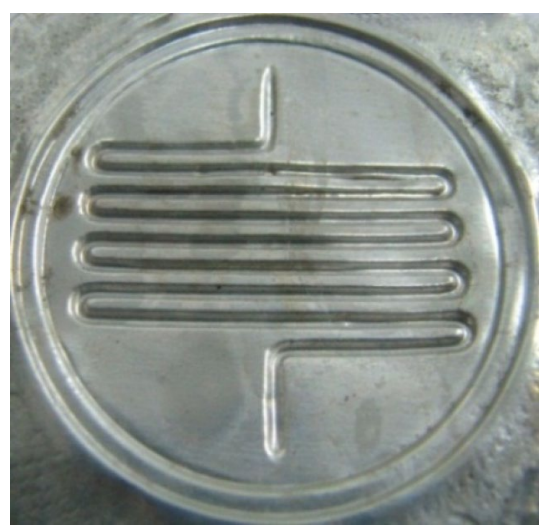

Fig. 6 Sample of a formed plate

in a resin to protect the cutting edge not only against distortion but also deformation. Then, the embedded samples were grinded and polished. Grinding process cleans up the surface of the specimen and helps it to be seen more obvious during microscopic imaging process. Polishing process eliminates the artifacts of grinding and removes tiny materials as well. Finally, the samples are ready for microscopic imaging. An example of microscopic image is depicted in Fig. 8. In order to measure the thickness along formed blank, the "Dewinter fluorescence microscope" which is attached with "Dewinter material plus" image analysis software has been used. The magnification of this microscope is in the range of $4 \times$ up to $100 \times$. To begin with, the microscope and its attached software were calibrated by standard gauges at specified magnification $(40 \times)$ in both $\mathrm{X}$-axis and $\mathrm{Y}$-axis 

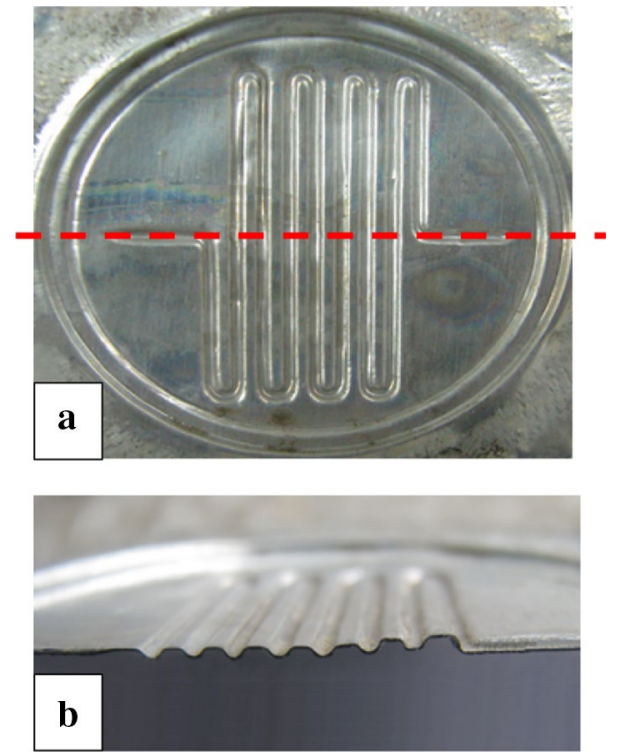

Fig. 7 a Cut direction, $\mathbf{b}$ cut section

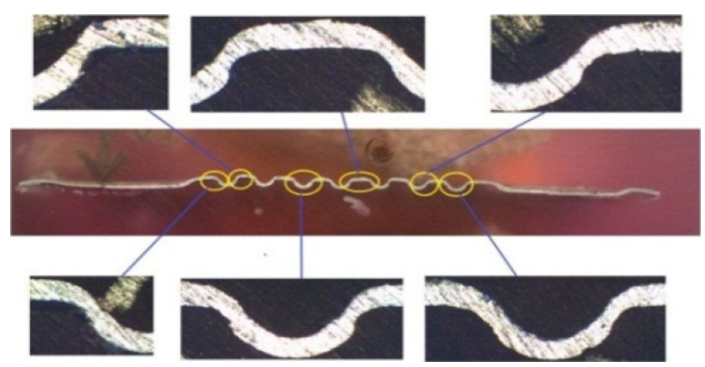

Fig. 8 Microscopic image from cut section

directions to make sure that the measurement equipment works properly and accurately. This device has the ability to measure a wide variety of elements such as straight line, angle, curved length, area and radios. To start measuring process, the image of specimen taken by attached camera is loaded. By clicking on the left bottom of the mouse on the starting point(lower surface of the blank) and drag the clicked mouse to the last point(upper surface of the blank), the coordination of

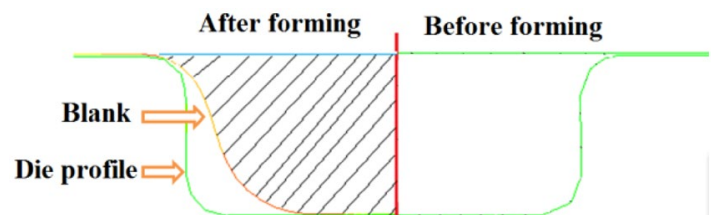

Fig. 10 Filling profile criteria

start point, end point and the length between two points will be calculated and reported in Excel file. The shortest distance between two points represents the thickness of blank at that location. In addition, for calculating the filling percentage, it is essential to measure the area of die which is filled by blank during formation process, and then comparing this area with the die cavity area. For this purpose, using "freehand area calculator" bottom of "Dewinter material plus" software, the area between blank and die is precisely outlined by dragging clicked mouse and release the left bottom of the mouse when the line is near to the starting point. The line is automatically meeting the starting point to enclose the specified area, and the results are reported. Thickness distribution and filling percentage is measured along specified path. This path, as demonstrated in Fig. 9, starts from the middle of channel width to the middle of rib width.

\subsubsection{Evaluation criteria}

In order to determining the amount of blank which is filled into the die cavity, a filling profile criterion was represented. According to this criterion, the space of the die which is swept by blank during forming is compared with the total space of die cavity. This index is represented in Fig. 10 and Eq. (3). Also, for indicating the amount of thinning in the formed blank, the thinning percentage criterion was represented. According to this criterion, the minimum thickness of formed blank is compared with the initial thickness of the blank. This index is represented in Eq. (4).
Fig. 9 Selected path for forming evaluation

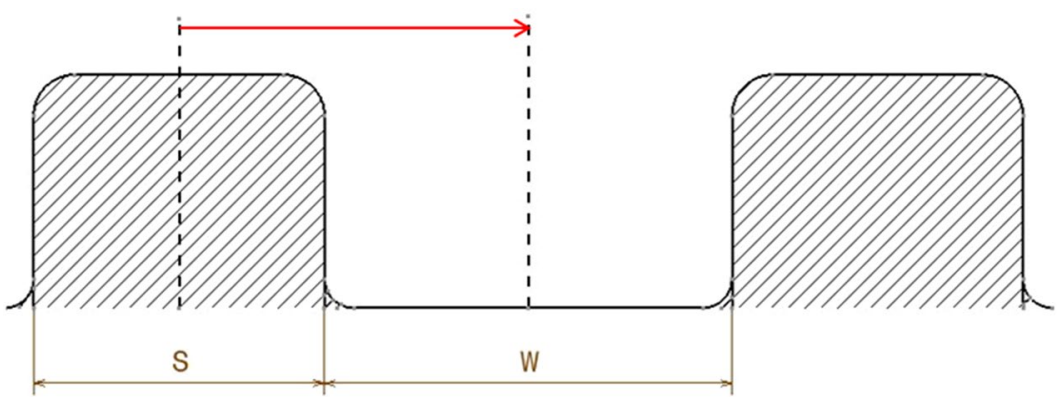

SN Applied Sciences A SPRINGER NATURE journa 
Filling profile percentage

$$
\begin{aligned}
= & \frac{\text { Total space of die cavity }- \text { Sweeped space by blank }}{\text { Total space of die cavity }} \\
& \times 100 \%
\end{aligned}
$$

prevent the flow of hot material into the flow channel. Therefore, the thinnest point of the bipolar plate occurs in this region. Moreover, the considerable amount of friction between hot blank and die could play a crucial role in material flowing process, and act as an obstacle to flowing

Thinning percentage $=\frac{\text { Blank initial thickness }- \text { Minimum thickness of formed blank }}{\text { Blank initial thickness }} \times 100 \%$

\section{Results and discussion}

\subsection{Thickness variation and thinning percentage}

It is obvious that during the forming process, the thickness of formed plate is reduced. The thickness distributions of all channels were almost the same. In addition, the thickness distribution of all channels was symmetrical. Therefore, in order to representing the thickness distribution, the half of the flow channel and half of the rib channel, was selected. Figure 11 demonstrates the thickness distribution along aforementioned path. This diagram is comparable with the results of Liu and Hua [13] which have the similar trend. The curve of thickness distribution can be divided into three regions. In the region $A$, reduction of thickness is slight due to the fact that the blank drawing process does not happen largely in this region. In the region $B$ (matched with external edge of the channel), the thickness of the blank decreases sharply due to the existence of considerably sharp edge which could easily

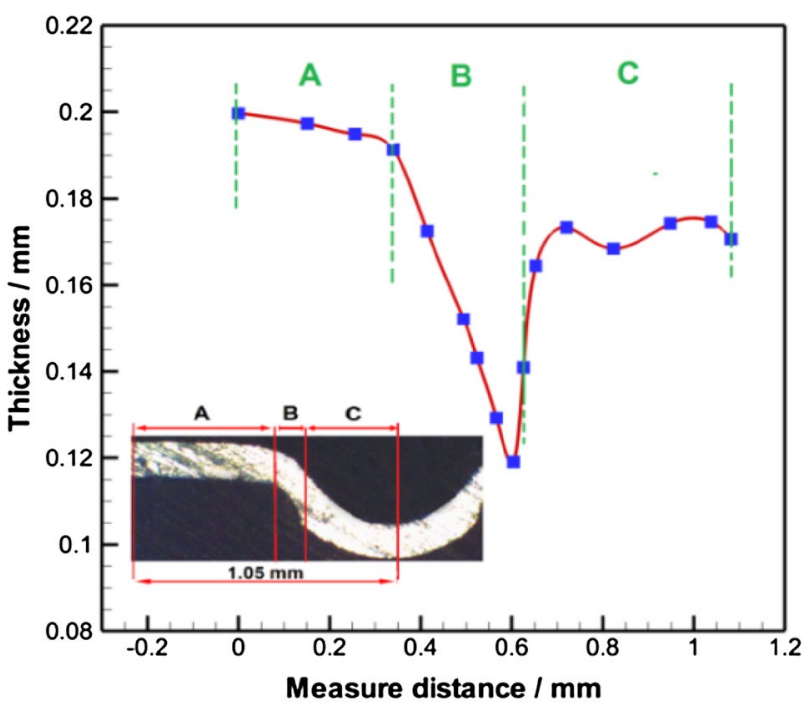

Fig. 11 Thickness distribution in $\mathrm{P}=3.2 \mathrm{MPa}$ for formed plate of the material into the flow channel. In region $C$, thickness distribution is not uniform. At the starting point, the thinning percentage is high owing to the fact that the surprising amount of the blank material is drawn into the flow channel. Reaching to the end of the region, its trend becomes smoother; although, the thickness of the blank is still lower than starting point of the region A. To investigate the effect of pressure on thickness distribution, five different values of pressure $P$ was applied varying from 1.8 MPa to $4 \mathrm{MPa}$. The results are shown in Fig. 12. It is clear that the trend appeared in Fig. 11 is repeated in Fig. 12 by applying different pressures. Moreover, by increasing the pressure, the thickness reduction happens in all regions because of the great amount of materials flowing into the die. It can be seen that by increasing the pressure up to $4 \mathrm{MPa}$, the thickness is decreased into 50 percent. To describe the effect of pressure on thickness reduction, the minimum thickness in formed bipolar plate was measured. This thinning almost happened in region $B$, which is in direct contact with external edge of channels. The results for five different pressures are depicted in Fig. 13. It can be observed that by increasing the applied pressure

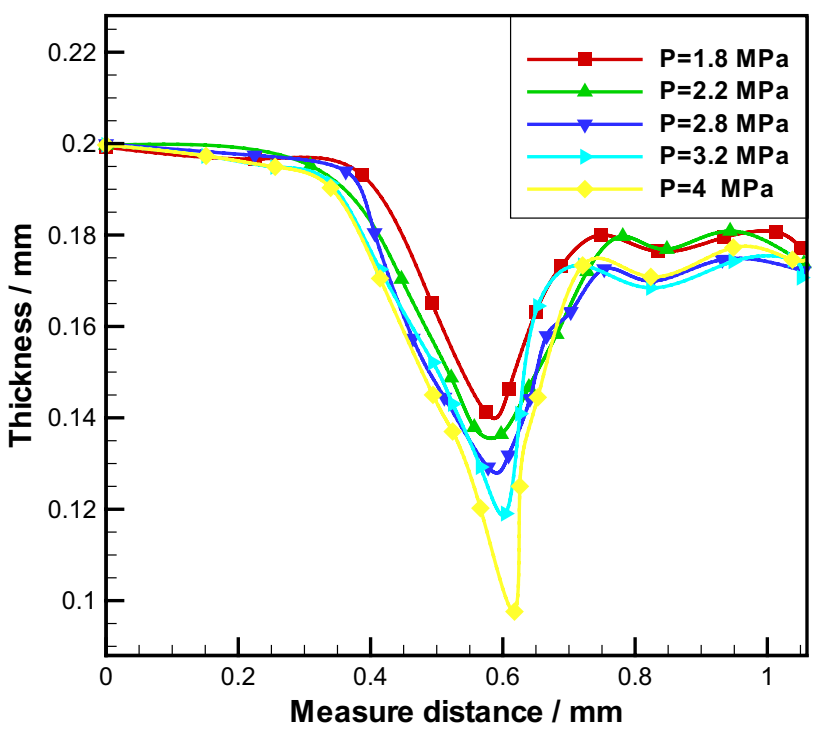

Fig. 12 Thickness distribution at different $P$ 

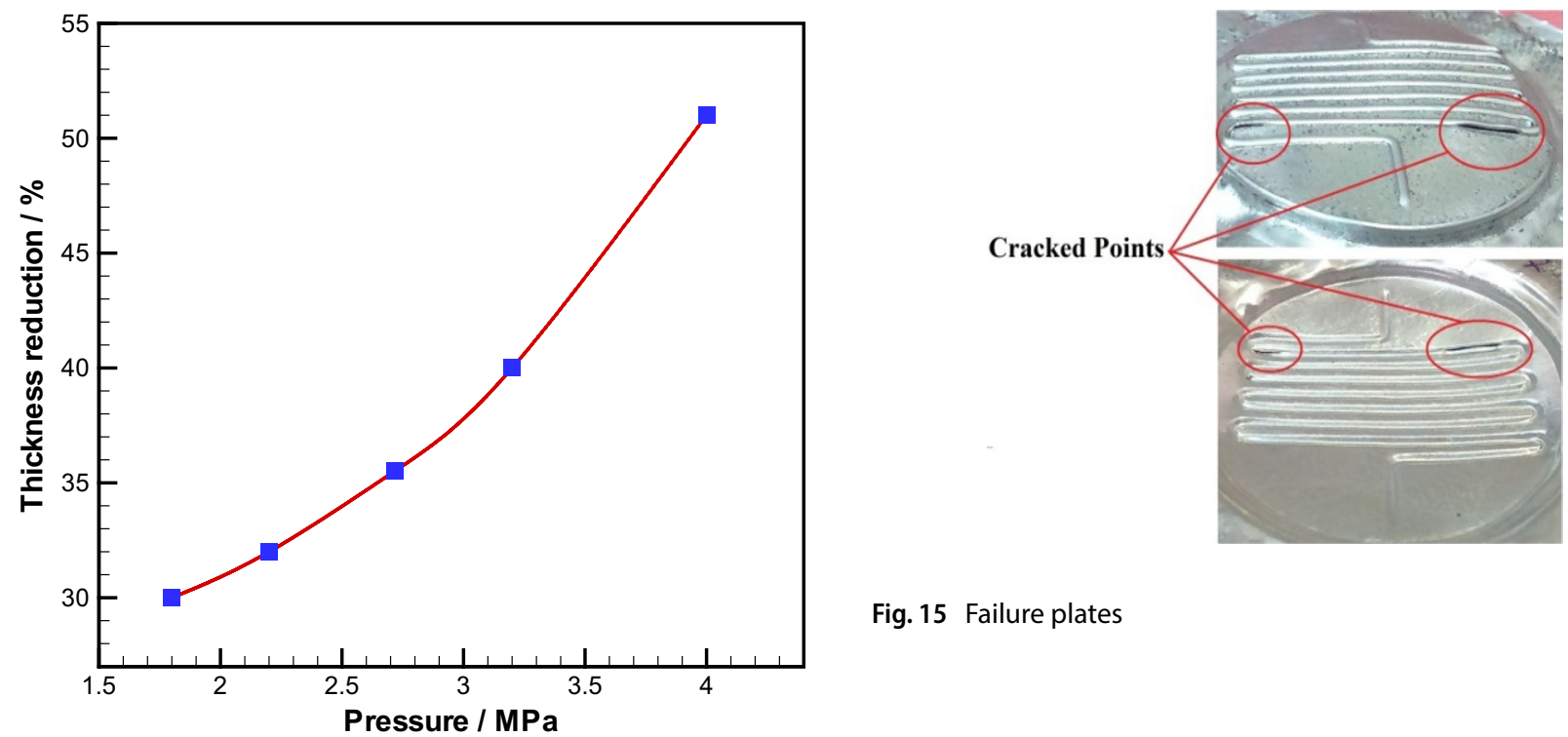

Fig. 15 Failure plates

Fig. 13 Thinning percentage at different $P(h / w=0.5)$
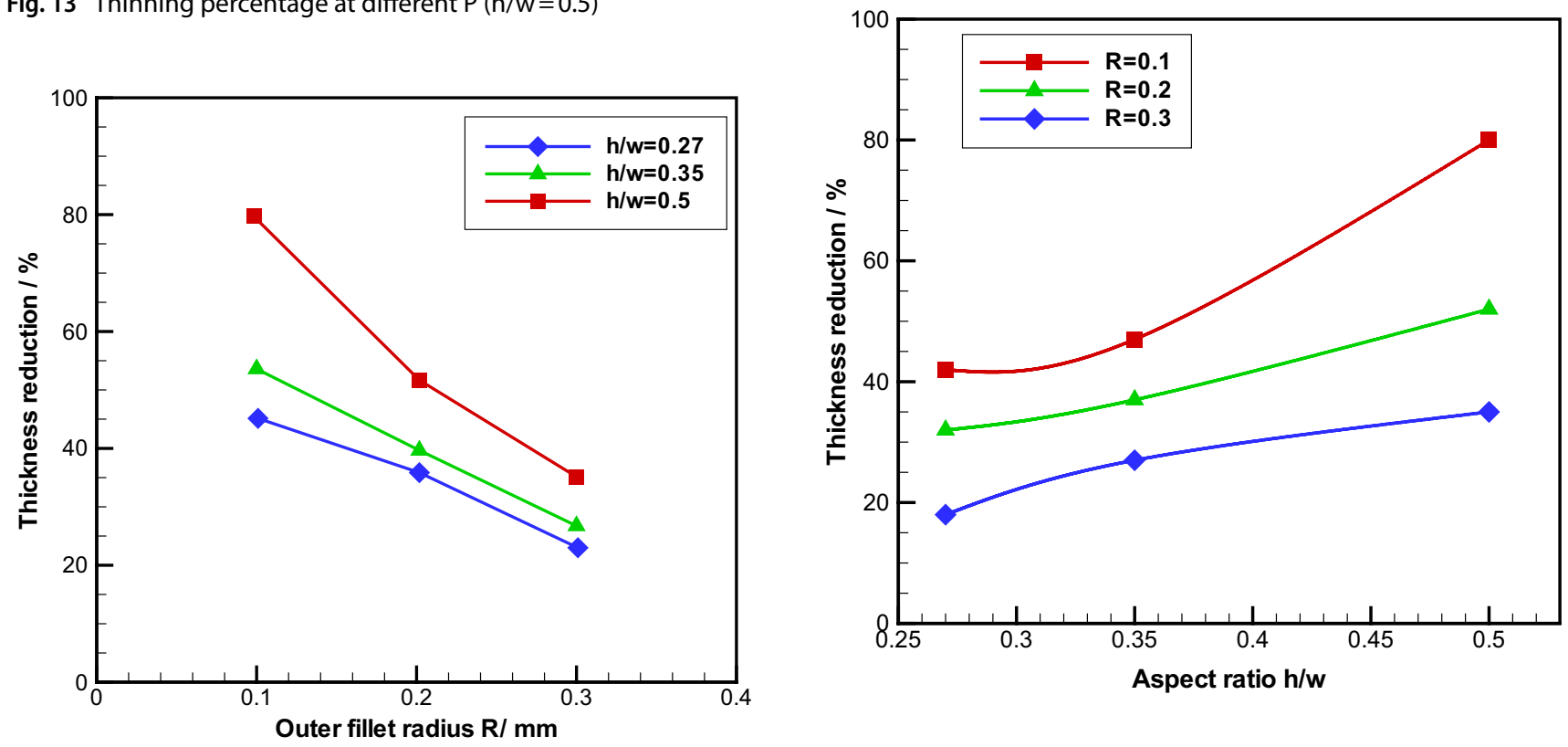

Fig. 16 Effect of $(\mathrm{h} / \mathrm{w})$ on thickness reduction

Fig. 14 Effect of outer fillet radius $\mathrm{R}$ on thickness reduction

$P$, the thickness reduction is increased. But, the thickness reduction has no uniform trend. As shown in Fig. 13, when $\mathrm{P}$ becomes more than $3.2 \mathrm{MPa}$, the thickness reduction increases sharply. This phenomenon can be explained by friction between the die and blank. Increasing pressure can cause the blank to be pushed into the flow channel; as a result, the blank is touched by 2 walls of flow channel. Hence, the normal flow of material will be cut off and the stretching process will be continued sharply in untouched regions.
The outer fillet radius $\mathrm{R}$ of rigid die has important role in forming process. To investigate the effect of this parameter, the R was considered from 0.1 to $0.3 \mathrm{~mm}$. As shown in Fig. 14, by increasing the outer fillet radius $R$, the thickness reduction is decreased. This can be explained by the fact that increase of $\mathrm{R}$ leads to elimination of the sharp edge on external corners of rigid. Hence, the blank can easily be drawn into the die space. When $\mathrm{R}$ is $0.1 \mathrm{~mm}$, the thickness reduction is almost high at most of the cases and they could be considered as critical points. Therefore, the blank might crack at the corners, but when $\mathrm{R}=0.2 \mathrm{~mm}$ or more, it 
leads to formation of an accurate bipolar plate without any crack. Two examples of cracked plates are demonstrated in Fig. 15. It is observed that the cracked points appear at the region of blank which is in direct contact with outer fillet edges.

Forming process at different aspect ratios ranging from 0.27 to 0.5 (shown in Fig. 16) has been investigated. It can be understood that increasing the h/w, speeds up the thickness reduction. This phenomenon can be explained by the fact that as the aspect ratio is increased and the rib width is fixed, the height of the flow channel is enhanced, which creates extra space in die, and allows the blank to be stretched more. According to the experimental observation, if the maximum thickness reduction reaches more than $50 \%$, the blank is cracked and considered as a failed part. When $R=0.1 \mathrm{~mm}$, by increasing $\mathrm{h} / \mathrm{w}$ to 0.35 or 0.5 , the thickness reduction will be at its highest value and the formed bipolar plate will be cracked.

\subsection{Filling profile and filling percentage}

To investigate the effect of pressure on filling profile, the profile of bipolar plates formed by five different pressure values were measured. The results are shown in Fig. 17. It is observed that applied pressure leads to pushing the blank into the die. At low pressures, filling profiles of bipolar plates are not complete. But, at higher pressures, its percentage will be increased. However, at high pressures there is no linear relationship. As an illustration, by increasing the pressure from 2.8 to $3.2 \mathrm{MPa}$, the filling percentage increased considerably; while, by enhancing the pressure from 3.2 to $4 \mathrm{MPa}$, the filling percentage is not changed largely as the blank is touched and limited by walls and ceiling of the channel. Thus, the blank is not permitted to be stretched considerably.

For more accurate investigation on the profile filling, the area of die cavity which is swept by blank was measured. Then, it was compared with total area of die cavity,

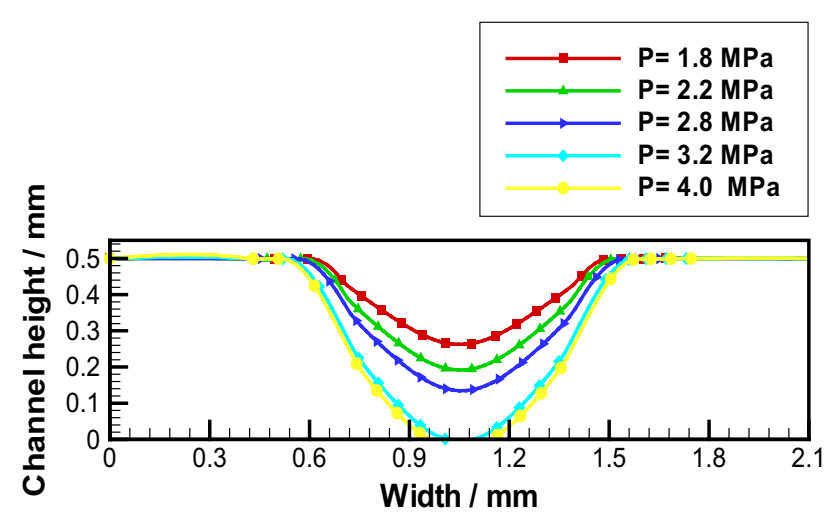

Fig. 17 Effect of different pressures on filling profile and was expressed in percent. The filling percentage at different pressures is shown in Fig. 18. It shows that by increasing the pressure, the filling percentage is increased. But, it did not have a uniform trend. At the early steps, by increasing $P$, the filling percentage increases rapidly. Since the blank is not in contact with the die set, it can be drawn easily into the die. But, by increasing the pressure, the blank meets the sides of the channel, and this phenomenon prevents the flow of material into the die cavity. Therefore, when $\mathrm{P}$ varied from 3.2 to $4 \mathrm{MPa}$, the filling percentage changed slightly from 74 to $80 \%$.

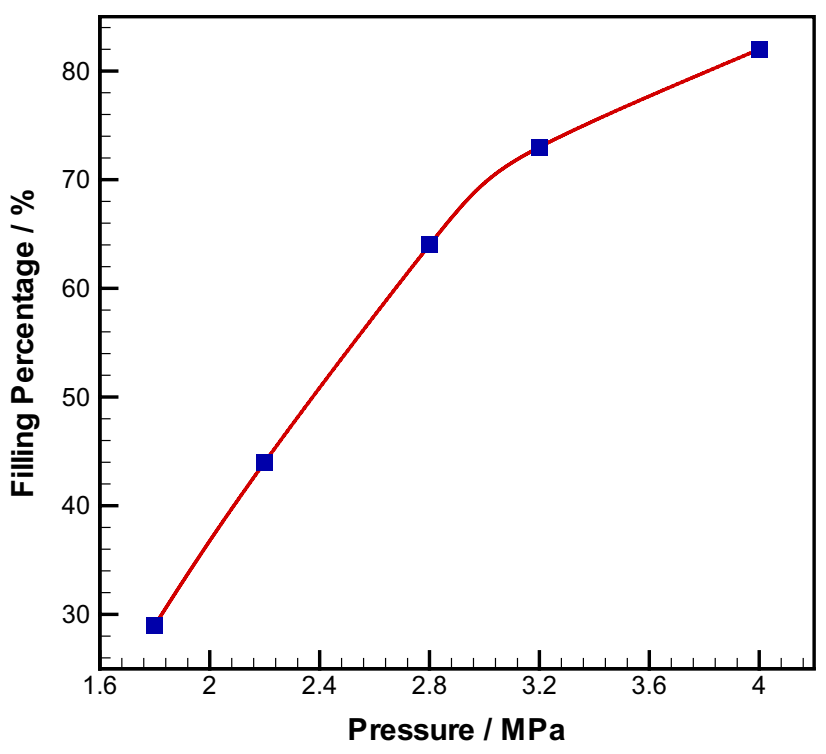

Fig. 18 Filling percentage at different pressures

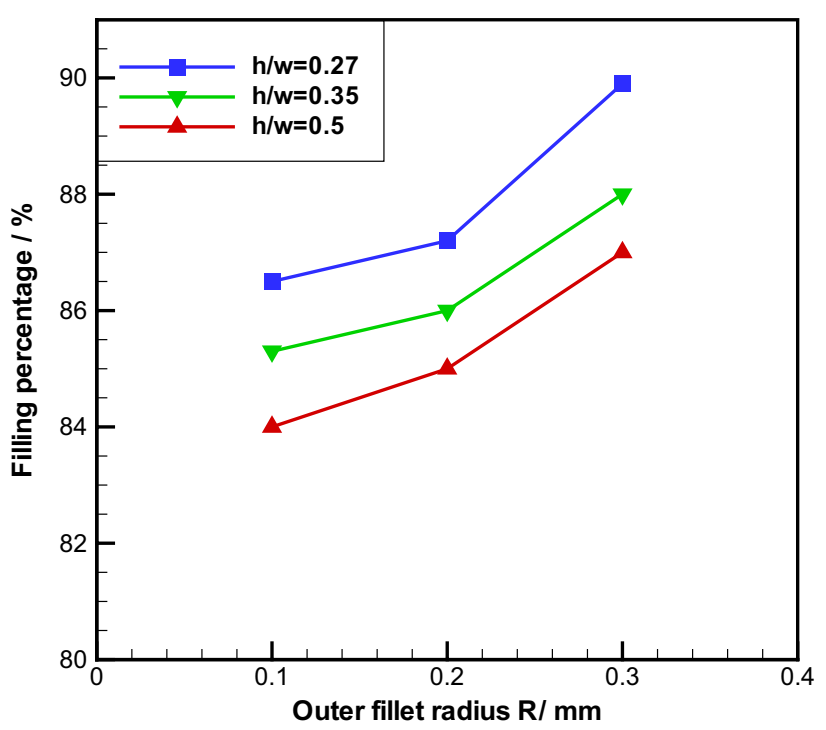

Fig. 19 The effect of outer fillet radius on filling percentage 
To investigate the effect of outer fillet radius $\mathrm{R}$ on the filling percentage, three dies with different outer fillet radius were prepared. Then, the area of die cavity which was filled by blank was measured. These results are represented in Fig. 19. The $R$ value varied from 0.1 to $0.3 \mathrm{~mm}$. It can be seen that the filling percentage rises by increasing of R. In other words, as R increases, the sharp edges of die are eliminated; as a result, the flow of blank material into the die cavity is facilitated. Consequently, the filling percentage will be increased. This trend is also observed at different aspect ratios from 0.27 up to 0.5 as is seen in Fig. 19 .

\subsection{Discussion}

According to the abovementioned results, the thickness distribution curve is divided into three main regions. The thinnest area of formed bipolar plate occurs in region $B$. This region is always in contact with the corner of channels. During the forming process, because of the friction between surfaces of the rigid die and the blank, the material can hardly flow into the die cavity; thus, local thinning happens in region B. By increasing the applied pressure, the thickness reduction is increased as well. Therefore, by increasing $\mathrm{P}$, the stretch percentage in bipolar plate is increased. But, thickness distribution is not uniform. At high pressures, the thickness reduction is increased rapidly. For instance, by increasing $P$ from 3.2 to $4 \mathrm{MPa}$, the thickness reduction increased from 41 to $52 \%$. On the other hand, by increasing $P$, the filling profile of formed bipolar plate will increase; as a result, the filling percentage is increased. But this trend isn't uniform. At low pressures, material can be easily flown into the die, and fill in the die cavity at initial time as the blank has no contact with sides of channels. By increasing $P$, the blank meets the sides of channels. Therefore, the friction between the die and blank increases, and prevent the material from flowing into the die cavity. In this condition, by increase of $\mathrm{P}$, the filling percentage increases slowly, but the thinning percentage increases rapidly. The outer fillet radius $R$ has an important role in the forming process. By increasing $R$, the sharp edges on the rigid die are eliminated, and the material can be flown easily into the die cavity; therefore, the filling percentage can be increased. When $R$ is 0.1 and $P$ is $4 \mathrm{MPa}$, because of existence the sharp edge, the local thinning happens at high $\mathrm{h} / \mathrm{w}$, and the formed bipolar plate is cracked. But, when $\mathrm{R}$ is $0.2 \mathrm{~mm}$ or more, the thickness reduction is less than $50 \%$ in most of the cases. Hence, it is acceptable for forming of bipolar plate. It can be claimed that $R$ has high effect on thickness reduction than the filling percentage. In order to investigate the effect of channel width on the forming process, three aspect ratios $(\mathrm{h} / \mathrm{w})$ consist of $0.27,0.35$ and 0.5 were applied, and the channel depth was held constant at $0.5 \mathrm{~mm}$. The experimental results showed that by increasing $\mathrm{h} / \mathrm{w}$, the filling percentage decreases, but thickness reduction increases. By increasing aspect ratio $\mathrm{h} / \mathrm{w}$, the channel width $\mathrm{w}$ becomes smaller and the blank is involved with more contact with sides of channels during forming process. Thus, the flow of material into die cavity becomes difficult.

\section{Summary and conclusions}

1. This study deals with fabrication of aluminum alloy bipolar plates by hot metal gas forming process. In experiments, the applied gas pressure was considered as an outstanding parameter of HMGF. Moreover, according to the almost papers which were dealing with fabrication of metallic bipolar plates, the die parameters were the corner stone in formability of blanks $[7,9,20]$. In this paper, some of these parameters, such as the outer fillet radius $R$ and flow channel width $w$, were considered as variable parameters. The other parameters such as flow channel depth h, rib width $s$ and internal fillet radius $r$ were supposed as fixed parameters. Two main criteria were considered in order to evaluating the forming state: filling profile and thickness distribution. The thickness distribution of formed blank had no uniform trend. It was divided into three regions, and the maximum thickness reduction occurred in region of blank which was in direct contact with edges of channels.

2. The outer fillet radius $R$ makes an outstanding contribution on thickness reduction. When $R$ is $0.1 \mathrm{~mm}$, at high aspect ratios, the thickness reduction is more than critical value, and crack appears in formed bipolar plate. But when the $\mathrm{R}$ is $0.2 \mathrm{~mm}$ or more, an acceptable formed plate is achievable. This conclusion is comparable with the reports of Liu et al. [13] which were studying on fabrication of bipolar plates by rubber pad forming pad forming at ambient temperature. They reported that when the $R$ was 0.1 and $0.2 \mathrm{~mm}$, the crack appeared in formed plates; while, by increasing the $\mathrm{R}$ to 0.3 , the non-cracked plate was achievable. Regardless of the blank's material and its thickness, this phenomenon can be explained by the temperature in which the experiments are carried out, and the fluidity of blank's material at two different temperatures. At HMGF method, thanks to the high temperature, the blank's material is more flexible than the one in rubber pad forming; therefore, there is no crack in formed plate when the $R$ is 0.2 .

3. By increasing the aspect ratio $h / w$, the thickness reduction is increased. Considering the fact that the channel depth $\mathrm{h}$ is considered as a fixed parameter, by increasing $\mathrm{h} / \mathrm{w}$ values, the blank is faced with more 
contact by vertical walls of the die. Therefore, a surprising amount of blank material is locked in contact area and is prevented to flowing into the die cavity. This phenomenon causes the forming process to be continued by limited amount of blank material, and as a result, the considerable amount of thickness reduction is occurred. This conclusion is comparable with the results of Liu et al. [14]. They studied on two deformation styles: concave and convex. The thickness reduction acquired from HMGF is highly matched with their results of concave deformation style. They reported that as aspect ratio h/w increases, the thickness reduction in concave style rises up as well. When $\mathrm{h} / \mathrm{w}=0.5$ and $\mathrm{R}=0.3$, the thickness reduction by rubber pad forming is $31.8 \%$; while, it is $35 \%$ in HMGF.

4. Since the process is performed at high temperature, the applied pressure is too low in comparison to the other methods. As an illustration, achieving to the filling percentage of $80 \%$, the applied pressure in hydroforming method [16] is about $50 \mathrm{MPa}$ and in HMGS is $4 \mathrm{MPa}$. Although the material properties and the thickness of blank in their study are different, the pressure is utilized in HMGS is considerably lower than the other methods. Moreover, argon, which is a neutral gas, is used for applied pressure; therefore, it does not have any side-effect on material properties of plates. One of the negative aspects of hot metal gas forming method is that it is time-consuming process duo to the reason of spending time for heating the die set, applying pressure, and cooling the die set.

Funding This study was self-funded and implemented in Hot Metal Gas Forming (HMGF) laboratory at mechanical engineering department of Babol University of technology.

\section{Compliance with ethical standards}

Conflict of interest The authors declare that they have no conflict of interest.

\section{References}

1. Hermann A, Chaudhuri T, Spagnol P (2005) Bipolar plates for PEM fuel cells: a review. Int J Hydrogen Energy 30(12):1297-1302

2. Li X, Sabir I (2005) Review of bipolar plates in PEM fuel cells: flow-field designs. Int J Hydrogen Energy 30(4):359-371

3. Weil KS, Xia G, Yang ZG, Kim JY (2007) Development of a niobium clad PEM fuel cell bipolar plate material. Int J Hydrogen Energy 32(16):3724-3733
4. Besmann T, Henry J, Klett J (2003) Development of a carbon composite bipolar plate. In: Proceedings of the fuel cell seminar, Miami Beach, FL, November, pp 61-64

5. Li MC, Liu TG, Zhao J, Meng Z (2006) Performance optimization and design of PEMFC thin metallic bipolar plates. JTianjin Univ 10:1252-1257

6. Mehta V, Cooper JS (2003) Review and analysis of PEM fuel cell design and manufacturing. J Power Sour 114(1):32-53

7. Kumar A, Reddy RG (2003) Effect of channel dimensions and shape in the flow-field distributor on the performance of polymer electrolyte membrane fuel cells. J Power Sour 113(1):11-18

8. Cha S, O'Hayre R, Saito Y, Prinz F (2004) The scaling behavior of flow patterns: a model investigation. J Power Sour 134(1):57-71

9. Koç M, Mahabunphachai S (2007) Feasibility investigations on a novel micro-manufacturing process for fabrication of fuel cell bipolar plates: internal pressure-assisted embossing of micro-channels with in-die mechanical bonding. J Power Sour 172(2):725-733

10. Lee S-J, Lee C-Y, Yang K-T, Kuan F-H, Lai P-H (2008) Simulation and fabrication of micro-scaled flow channels for metallic bipolar plates by the electrochemical micro-machining process. J Power Sour 185(2):1115-1121

11. Yokoyama M, Yamaura S-I, Kimura H, Inoue A (2008) Production of metallic glassy bipolar plates for PEM fuel cells by hot pressing in the supercooled liquid state. Int J Hydrogen Energy 33(20):5678-5685

12. Hung J-C, Yang T-C, K-C Li (2011) Studies on the fabrication of metallic bipolar plates-Using micro electrical discharge machining milling. J Power Sour 196(4):2070-2074

13. Liu $Y$, Hua $L$ (2010) Fabrication of metallic bipolar plate for proton exchange membrane fuel cells by rubber pad forming. J Power Sour 195(11):3529-3535

14. Liu Y, Hua L, Lan J, Wei X (2010) Studies of the deformation styles of the rubber-pad forming process used for manufacturing metallic bipolar plates. J Power Sour 195(24):8177-8184

15. Lim S, Kim Y, Kang C (2013) Fabrication of aluminum 1050 microchannel proton exchange membrane fuel cell bipolar plate using rubber-pad-forming process. Int J Adv Manuf Technol 65(1-4):231-238

16. Belali-Owsia M, Bakhshi-Jooybari M, Hosseinipour S, Gorji A (2015) A new process of forming metallic bipolar plates for PEM fuel cell with pin-type pattern. Int J Adv Manuf Technol 77(5-8):1281-1293

17. Ghadikolaee HT, Elyasi M, Khatir FA, Hosseinzadeh M (2017) Experimental investigation of Fracture in rubber pad forming of bipolar plate's micro channels. Proced Eng 207:1647-1652

18. Giuliano G, Franchitti S (2007) On the evaluation of superplastic characteristics using the finite element method. Int J Mach Tools Manuf 47(3-4):471-476

19. Giuliano G, Franchitti S (2008) The determination of material parameters from superplastic free-bulging tests at constant pressure. Int J Mach Tools Manuf 48(12-13):1519-1522

20. Peng L, Lai X, Hu P, Ni J (2008) Flow channel shape optimum design for hydroformed metal bipolar plate in PEM fuel cell. $J$ Power Sour 178(1):223-230

Publisher's Note Springer Nature remains neutral with regard to jurisdictional claims in published maps and institutional affiliations. 